\title{
Regional and Field-Specific Factors Affect the Composition of Fusarium Head Blight Pathogens in Subtropical No-Till Wheat Agroecosystem of Brazil
}

\author{
Emerson M. Del Ponte, Piérri Spolti, Todd J. Ward, Larissa B. Gomes, Camila P. Nicolli, \\ Paulo R. Kuhnem, Cleiltan N. Silva, and Dauri J. Tessmann
}

First, second, fourth, fifth, and sixth authors: Departamento de Fitossanidade, Universidade Federal do Rio Grande do Sul, Porto Alegre, RS, Brazil 91540000; third author: United States Department of Agriculture-Agricultural Research Service, Peoria, IL; and seventh and eighth authors: Departamento de Agronomia, Universidade Estadual de Maringá, Maringá, PR, Brazil.

Current address of E. M. Del Ponte: Departmento de Fitopatologia, Universidade Federal de Viçosa, Viçosa, MG, Brazil $36570-900$.

Accepted for publication 31 July 2014.

\begin{abstract}
Del Ponte, E. M., Spolti, P., Ward, T. J., Gomes, L. B., Nicolli, C. P., Kuhnem, P. R., Silva, C. N., and Tessmann, D. J. 2015. Regional and field-specific factors affect the composition of Fusarium head blight pathogens in subtropical no-till wheat agroecosystem of Brazil. Phytopathology 105:246-254.

A multiyear survey of $>200$ wheat fields in Paraná (PR) and Rio Grande do Sul (RS) states was conducted to assess the extent and distribution of Fusarium graminearum species complex (FGSC) diversity in the southern Brazilian wheat agroecosystem. Five species and three trichothecene genotypes were found among 671 FGSC isolates from Fusarium head blight (FHB)-infected wheat heads: F. graminearum (83\%) of the 15-acetyldeoxynivalenol (15-ADON) genotype, F. meridionale $(12.8 \%)$ and $F$. asiaticum $(0.4 \%)$ of the nivalenol (NIV) genotype, and $F$. cortaderiae $(2.5 \%)$ and $F$. austroamericanum ( $0.9 \%)$ with either the NIV or the 3-ADON genotype. Regional differences in FGSC composition were observed, with $F$. meridionale and the NIV type being significantly $(P<0.001)$ more prevalent in PR $(>28 \%)$ than in RS $(\leq 9 \%)$. Within RS, F. graminearum was overrepresented in fields below $600 \mathrm{~m}$ in elevation and in fields with higher levels of FHB incidence $(P<0.05)$.

Species composition was not significantly influenced by previous crop or the stage of grain development at sampling. Habitat-specific differences in FGSC composition were evaluated in three fields by characterizing a total of 189 isolates collected from corn stubble, air above the wheat canopy, and symptomatic wheat kernels. Significant differences in FGSC composition were observed among these habitats $(P<0.001)$. Most strikingly, F. meridionale and $F$. cortaderiae of the NIV genotype accounted for the vast majority (>96\%) of isolates from corn stubble, whereas $F$. graminearum with the 15-ADON genotype was dominant (>84\%) among isolates from diseased wheat kernels. Potential differences in pathogenic fitness on wheat were also suggested by a greenhouse competitiveness assay in which $F$. graminearum was recovered at much higher frequency $(>90 \%)$ than $F$. meridionale from four wheat varieties inoculated with an equal mixture of $F$. graminearum and $F$. meridionale isolates. Taken together, the data presented here suggest that FGSC composition and, consequently, the trichothecene contamination in wheat grown in southern Brazil is influenced by host adaptation and pathogenic fitness. Evidence that $F$. meridionale and $F$. cortaderiae with the NIV genotype are regionally significant contributors to FHB may have significant implications for food safety and the economics of cereal production.
\end{abstract}

Fusarium head blight (FHB) is a fungal disease of major economic concern to small grain production worldwide, particularly due to contamination of grain with dangerous mycotoxins produced by the fungus during pathogenesis $(15,25)$. The $F u$ sarium graminearum species complex (FGSC), which comprises at least 16 recognized species $(31,32,46,52,62)$, is the primary cause of FHB in many parts of the world. Among members of the FGSC, $F$. graminearum is the most prevalent species, causing FHB in many parts of the world, and is particularly dominant among isolates from wheat in Europe $(55,61)$ and the Americas $(3,42,59)$. In South America, six other species within the FGSC have been found affecting wheat and other cereal crops grown in Brazil, Argentina, and Uruguay, including F. asiaticum, F. austroamericanum, $F$. boothii, $F$. brasilicum, $F$. cortaderiae, and F. meridionale $(2,3,32,44,49,56)$.

FGSC species are known to produce several mycotoxins but special attention has been given to trichothecenes, which are harmful for both human and animal health (11). Deoxynivalenol $(\mathrm{DON})$ is the most significant among the trichothecenes, given its

Corresponding author: E. M. Del Ponte; E-mail address: delponte@ufv.br

http://dx.doi.org/10.1094/PHYTO-04-14-0102-R

(c) 2015 The American Phytopathological Society widespread occurrence in wheat grain at levels of concern. Due to the difficulties associated with the preharvest management of FHB, several countries promulgated maximum limits for mycotoxin contamination in grains and foods, especially for DON (57). However, nivalenol (NIV), another trichothecene mycotoxin, has been observed at equal or higher concentrations than DON in the Netherlands, Japan, and Brazil (10,53,54).

Three strain-specific profiles of trichothecene production, or chemotypes, have been identified among members of the FGSC, including NIV and its acetyl-derivatives, DON and primarily 3acetyldeoxynivalenol (3-DON), and DON and primarily 15ADON (26). Trichothecene chemotype diversity has been maintained by selection, indicating that chemotype differences can have important consequences for the fitness of the producing organism (58). The genetic basis for chemotype differences has also been identified $(1,20,22)$, and several polymerase chain reaction (PCR)-based assays are available for genetic determination of the trichothecene chemotype potential of individual isolates $(7,39,58,59)$. In addition, a multilocus genotyping (MLGT) assay based on interrogation of single-nucleotide polymorphisms located in several housekeeping genes and genes involved in trichothecene biosynthesis has been developed for simultaneous determination of species identity and trichothecene genotype $(31,46,59,62)$. Although inconsistencies between the trichothe- 
cene genotype and the chemotype of some isolates have been infrequently reported $(28,45)$, these molecular assays constitute useful tools for mapping trichothecene genotype distributions and conducting large-scale molecular surveillance of FGSC composition $(2,33,36,40,42,49,59)$.

In Brazil, two molecular surveys for the identification of FGSC and trichothecene genotypes have been conducted in wheat. The first analyzed a collection of 82 isolates obtained from Fusariumdamaged kernels harvested across three states (49) and the second analyzed three collections of $\approx 50$ isolates each from three individual fields (3). Both studies showed the presence of only $F$. graminearum and $F$. meridionale, although four other species of the complex have been documented in Brazilian isolates collected from small grain cereals and soybean seed $(2,23,32)$.

The main objectives of the present study were to expand knowledge of the species composition and toxigenic potential of FHB pathogens in southern Brazil using a much larger collection of FHB isolates and to improve understanding of the factors affecting species composition based on both field survey and experimental data. An additional objective was to evaluate differences in species composition from collections of isolates obtained from within-field corn residues, the air above the wheat canopy, and infected wheat kernels. These field survey and experimental data were used to test our hypotheses that the FGSC composition on wheat in southern Brazil is (i) more diverse than previously documented, (ii) influenced by region- or field-specific factors in no-tilled wheat crops following soybean or corn, and (iii) influenced by differences in ecology or pathogenic fitness on wheat among members of the FGSC.

\section{MATERIALS AND METHODS}

FHB survey and regional collection of isolates. Isolates that composed the regional collection were obtained from symptomatic wheat spikes collected during visits to commercial wheat fields in Rio Grande do Sul (RS) and Paraná State (PR), Brazil. In $\mathrm{RS}$, we visited fields from the major wheat-growing region in the northern portion of the state during October and November of three consecutive cropping years (2009 to 2011). From 49 to 60 fields were assessed per year, totaling 160 fields (Fig. 1). In each field, 20 sampling units separated by $\approx 10 \mathrm{~m}$ were randomly assigned following a $\mathrm{W}$-shape sampling design. In each sampling unit, 10 spikes from contiguous main tillers were sampled. Crop developmental stage according to Zadoks scale (63) at sampling, previous summer crop (corn or soybean) based on visible crop stubble, latitude and longitude coordinates, and the elevation above sea level was recorded for each of these fields. In the laboratory, each spike was rated visually for FHB incidence (spike is symptomatic or not) and severity (proportion of diseased spikelets per total spikelets). In PR, commercial wheat fields were visited from July to August during 2009 and 2011. In 2009, the samplings were made in both northern and southern locations at 25 municipalities. In 2011, all isolates were obtained from three municipalities in the southern region of PR state (Fig. 1).

Analyses of habitat-specific differences in FGSC composition. Three field settings were established in the northern region of RS state during 2011. They were named Santa Bárbara (SBA), Marau (MAR), and Vacaria (VAC), based on the municipality in which they were located. These fields were 240 to $260 \mathrm{~km}$ apart and at similar latitude (latitude 28.3 to 28.5 ) but varying longitude, SBA being the western-most location (longitude -53.25), MAR being centrally located (longitude -52.78 ), and VAC in the eastern portion (longitude -50.93) of the state. The fields were nontilled and had visible corn stubble at the soil surface. Two wheat cultivars, 'BRS Guamirim' and 'Quartzo', which are known as moderately susceptible and susceptible to FHB, respectively, were sown. FHB intensity was assessed 3 to 4 weeks after flowering and 50 wheat spikes were randomly collected at the three central rows of each of the four plots. The spikes were taken to the laboratory, where visual assessments of FHB incidence and severity were made. The plots were hand harvested in an area of $5 \mathrm{~m}^{2}$ and threshed mechanically using seed cleaning equipment, as described elsewhere (51). The incidence of Fusarium-damaged kernels (FDK, \%) (small and shrunken kernels with or without pink or white mycelia) was assessed visually in at least 100 mature kernels.

The collection of isolates in each field was made at three distinct habitats related to different stages in the life cycle of the fungus: corn stubble (survival stage), air above the canopy (dispersal stage), and infected kernel (infection and colonization stages). These collections are referred to as saprophytic, airborne, and pathogenic, respectively.

The saprophytic collection was obtained during visits to the fields during the stem elongation stage of crop development. In all, $\approx 50$ segments of corn stubble exhibiting black-colored perithecia were collected per field. The airborne collection was composed of fungal isolates taken from FGSC-like colonies grown in petri plates containing Nash-Snyder medium (6) mounted on stationary spore traps that were positioned $0.5 \mathrm{~m}$ above the canopy $(9,47)$. The samplings were made during five consecutive nights when the crop was at the full-flowering stage. On each night, five plates were placed at $1700 \mathrm{~h}$ and collected at $0900 \mathrm{~h}$. After each collection period, the plates were covered with a lid and returned to the laboratory for incubation. To compose the pathogenic collection, Fusarium-damaged mature kernels from the bulk of harvested kernels from the plots were carefully selected, surface disinfested, and incubated on potato-dextrose agar (PDA) medium.

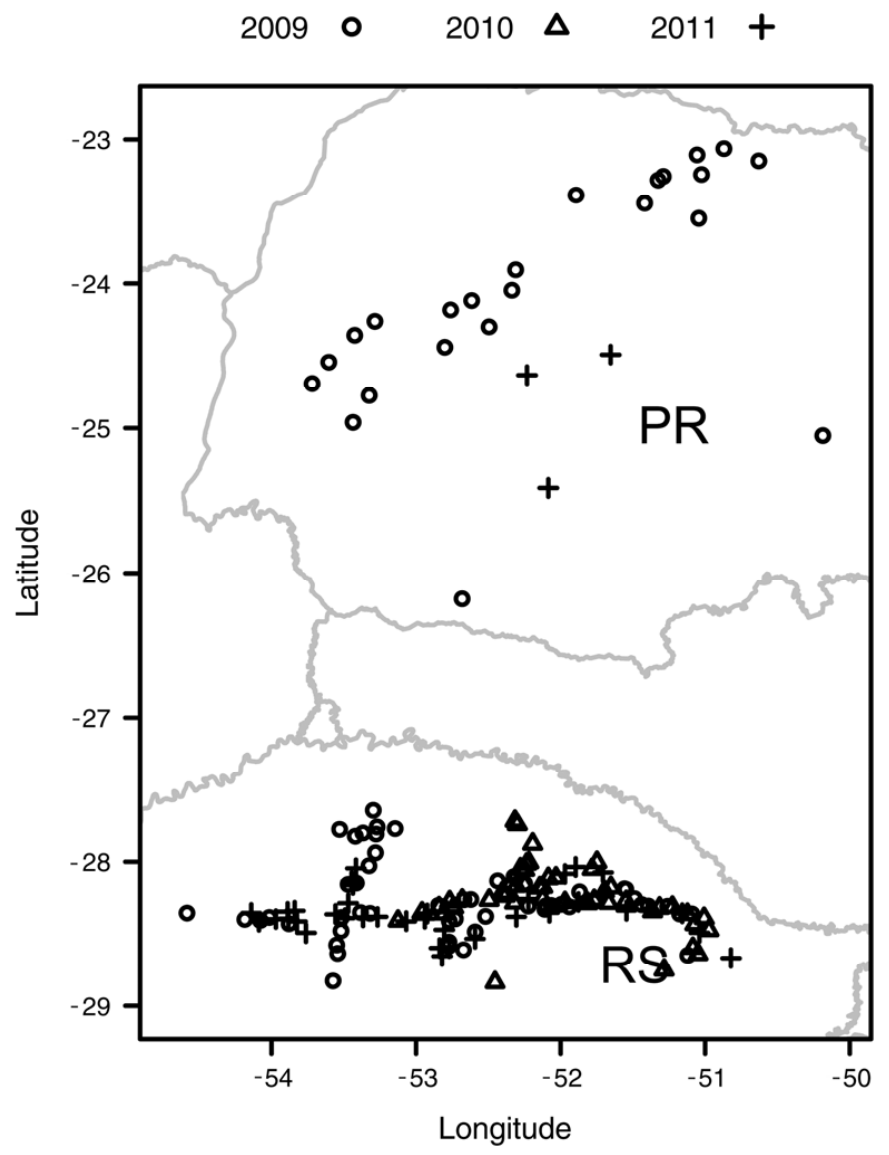

Fig. 1. Geographic locations of (i) commercial wheat fields surveyed for Fusarium head blight incidence, severity, and Fusarium graminearum species complex (FGSC) isolates in Rio Grande do Sul (RS) state from 2009 to 2011 and (ii) municipalities where commercial wheat fields were surveyed for FGSC isolates during 2009 and 2011 in Paraná (PR) state. 
Isolation and purification procedures. The isolates from the regional collection were obtained from symptomatic spikelets that were excised and incubated under wet conditions inside a plastic box containing a wet blotter paper. After 7 to 10 days, isolations were made from colonies resembling FGSC. A single isolate was obtained from one spike. For the saprophytic collection of isolates, fragments of corn stubble were immersed in $0.2 \%$ sodium hypochlorite for $30 \mathrm{~s}$, rinsed three times in sterile deionized water, blotted dry on sterile filter paper, and stored at $4{ }^{\circ} \mathrm{C}$ until processing. Prior to processing, small segments were surface disinfected in $70 \%$ ethanol for $30 \mathrm{~s}$ and $0.2 \%$ sodium hypochlorite for $30 \mathrm{~s}$, then rinsed three times in sterile deionized water. Under the microscope, a single perithecium was removed from the segment and placed on PDA plates containing streptomycin at $40 \mathrm{mg} / \mathrm{liter}$ (37). For the airborne collection, plates containing the selective media exposed to the air above the canopy were incubated for 5 to 7 days at room temperature $\left(22^{\circ} \mathrm{C}\right)$ under ambient light conditions. Salmon-colored colonies that developed on the selective media were subcultured onto fresh plates of PDA (47). Finally, the pathogenic collection of isolates was obtained from typical FGSC colonies grown from Fusarium-damaged kernels plated on PDA. All isolates were purified following a single-spore subculture and were prepared for long-term preservation as described previously (3).

Genomic DNA extraction. Prior to DNA extraction, the purified isolates were grown on a PDA plate for 7 days and the mycelia were removed, dried in filter paper, and stored at $4^{\circ} \mathrm{C}$. Genomic DNA was extracted using the cetyltrimethylammonium bromide (CTAB) protocol with some modifications, as described previously (3). The mycelia were macerated in liquid nitrogen and transferred to microtubes $(1.5 \mathrm{ml})$ where $750 \mu \mathrm{l}$ of CTAB $(2 \%$ CTAB, $1.4 \mathrm{M} \mathrm{NaCl}, 100 \mathrm{mM}$ Tris- $\mathrm{HCl}$ [pH 8], and $20 \mathrm{mM}$ EDTA [pH 8]) and $15 \mu \mathrm{l}$ of $\beta$-mercaptoetanol were added. Tubes were incubated for $15 \mathrm{~min}$ at $65^{\circ} \mathrm{C}$, and $500 \mu \mathrm{l}$ of chloroform/isoamilic alcohol (24:1) solution was used for extraction. After centrifuging at $11,000 \mathrm{rpm}$ for $10 \mathrm{~min}, 500 \mu \mathrm{l}$ of the supernatant were transferred to another microtube, and $5 \mu$ of RNAse suspension at $20 \mathrm{mg} / \mathrm{ml}$ was added. Tubes were incubated in hot-tube at $37^{\circ} \mathrm{C}$ for $30 \mathrm{~min}$. DNA was precipitated with $500 \mu \mathrm{l}$ of isopropanol, and $250 \mu \mathrm{l}$ of $7.5 \mathrm{M}$ ammonium acetate was added. After centrifuging at $11,000 \mathrm{rpm}$ for $10 \mathrm{~min}$, the supernatant was discarded and the pellet washed off in $100 \mu \mathrm{l}$ of $70 \%$ ethanol solution. The pellet was resuspended in $100 \mu \mathrm{l}$ of Tris-EDTA $(10 \mathrm{mM}$ Tris- $\mathrm{HCl}$ [pH 7.5] and 0.1 mM EDTA).

Species and trichothecene genotype identification. Most isolates were simultaneously assigned to an FGSC species and trichothecene genotype via MLGT using a Luminex 100 flow cytometer, as described previously (59). The MLGT assay was based on allele-specific primer extension using a 48-probe set $(46,59,62)$ targeting species and trichothecene chemotype-specific genetic variation in six genes. A subset of isolates were identified to species based on the analysis of partial sequences of the transcription elongation factor $1 \alpha$ gene (30) and further sequence similarity searches with BLAST network service of the Fusarium ID database (http://isolate.fusariumdb.org/blast.php) $(14,35)$. The trichothecene genotypes of those isolates were determined via multiplex PCR assays targeting portions of the Tri3 and Tri12 genes $(58,59)$ under the conditions described previously $(3)$.

Interspecies competition pathogenicity assay. Four wheat varieties varying in FHB resistance were used: 'BRS 194', classified as susceptible; 'BRS Guamirim', classified as a moderately susceptible; 'Frontana', classified as a moderately resistant; and 'Sumai 3', classified as resistant to FHB. Seed were sown in pots (10 seeds per 5-liter pot) containing substrate (equal parts of humus, soil, and vermiculite) fertilized with macronutrients (N-P-K at 10:10:10). Pots were maintained in the greenhouse from planting to flowering. Mean daily temperature was $25^{\circ} \mathrm{C}$, mean minimum temperature was $20^{\circ} \mathrm{C}$, and mean relative humidity was $60 \%$ in the greenhouse during the experiment. The plants were spray inoculated with a macroconidial suspension $\left(1 \times 10^{5} \mathrm{spores} / \mathrm{ml}\right)$ at early-milk grain stage (8). The inoculum was composed of four isolates: two $F$. graminearum and two $F$. meridionale that had been previously characterized as highly pathogenic (50). The final concentration was adjusted ( $\mathrm{vol} / \mathrm{vol}$ ) for equal concentration of each isolate (1:1:1:1). After inoculation, plants were individually covered with a plastic bag and incubated at $\approx 25^{\circ} \mathrm{C}$ during $48 \mathrm{~h}$ in a growth chamber. Afterward, the bag was removed and the plants were moved back into the greenhouse. Assessment of disease severity was made at the 16th day after inoculation. The experiment was in a randomized complete block design with three replicates, a replicate being composed of potted plants with 10 spikes. At kernel maturity, grains were hand harvested and hand threshed, and FDK were surface disinfested and incubated on PDA medium. The recovered isolates were single spored and identified to one of the four inoculated isolates based on a vegetative compatibility assay (24). For such, four mycelial plugs of a distinct recovered isolate were placed equidistantly around the outer edge of a petri dish filled with V8-wheat medium $(150 \mathrm{ml}$ of V8 juice, $20 \mathrm{~g}$ of ground wheat seed, and $20 \mathrm{~g}$ of agar per 1 liter of medium) (24). A mycelial plug of the inoculated isolate was placed at the center of the plates, which were incubated at room temperature $\left(22^{\circ} \mathrm{C}\right)$ and continuous light. After 10 days, the presence of barrage zones at the junctions of growing colonies was indicative of an incompatible reaction. Our previous experiments showed that the inoculated isolates always showed absence or presence of barrage zones when paired with its clone or cultures of the other isolate, respectively. The experiment was repeated once. Results were similar between the experiments and the data from the second experiment are presented.

Data analyses. The $\chi^{2}$ test $(P<0.05)$ was used to evaluate differences in species composition in relation to year, state, and categorical field-specific factors for fields from RS state: field elevation above sea level, previous crop, grain stage at sampling, and FHB incidence. Also, the $\chi^{2}$ test and Fisher's exact test (for small sample size) were used to compare frequencies of the species grouped by prevalence (most dominant, second in dominance, and others) among the three habitats of all fields combined and frequencies of the species among the fields for all habitats combined. Finally, the same test was used to evaluate differences in the frequencies of $F$. graminearum and $F$. meridionale isolates recovered from spikes that were inoculated with an equal mixture of isolates of both species in a competitiveness assay.

\section{RESULTS}

Species and trichothecene genotypes in the regional collection. Five species within the FGSC were found in the regional collection of 671 isolates, in order of prevalence: F. graminearum (83\%), F. meridionale (12.8\%), F. cortaderiae (2.5\%), F. austroamericanum $(0.9 \%)$, and $F$. asiaticum $(0.4 \%)$ (Table 1$)$. The two most common species ( $F$. graminearum and $F$. meridionale) were widely distributed across the surveyed production regions (Fig. $2)$. Two of the less frequent $(<3 \%)$ species, $F$. asiaticum and $F$. cortaderiae, were found only in RS state, and F. austroamericanum was found in both states in similarly low frequencies (Fig. 2).

All three trichothecene genotypes were observed: 15-ADON was the most common (83.1\%), followed by NIV (15.4\%) and 3-ADON (1.34\%). 15-ADON and NIV isolates were observed in each of the annual collections from both PR and RS states, whereas 3-ADON isolates were observed only during 2010 in RS state and 2011 in PR state (Fig. 2).

The variation in the trichothecene genotype of the isolates was highly structured in relation to species differences (Fig. 2). All $557 \mathrm{~F}$. graminearum isolates were of the $15-\mathrm{ADON}$ trichothecene genotype (Fgra15A) and all but one of the 86 F. meridionale 
isolates were of the NIV genotype (FmerNIV) (Fig. 2). The identification of a single 15-ADON $F$. meridionale isolate was confirmed following independent culturing and DNA extraction. The three F. asiaticum isolates were of the NIV genotype. Isolates with either NIV or 3-ADON genotypes were observed within $F$. cortaderiae (FcorNIV and Fcor3A) and F. austroamericanum, with NIV predominating $(82.4 \%)$ among $F$. cortaderiae isolates and 3-ADON being more common (75\%) among $F$. austroamericanum isolates. F. austroamericanum isolates of the NIV genotype were found only in PR State (Fig. 2).

The relative frequencies of $F$. meridionale and the NIV genotype were significantly $(P<0.0001)$ higher in PR State $(28.2$ and $29.2 \%$, respectively) compared with RS State (5.5 and $9 \%$ respectively), with corresponding differences in the frequencies of F. graminearum and the 15-ADON genotype (Table 1; Figs. 2 and $3)$. Within each state, species composition did not change significantly across the sampled years $(P>0.17)$.

Exclusively for the collection of isolates from RS, where fieldspecific data were available, the $\chi^{2}$ tests showed weak evidence for the effect of FHB incidence $\left(\chi^{2}=6.23, P=0.044\right)$ (Fig. 4D) and field elevation above the sea level $\left(\chi^{2}=6.11, P=0.046\right)$ (Fig. 4A) on FGSC composition. F. graminearum was overrepresented in fields below $600 \mathrm{~m}$ in elevation and in fields with higher levels of FHB incidence $(P<0.05)$. However, there was no evidence that species composition was influenced by previous crop $\left(\chi^{2}=\right.$ $1.92, P=0.38$ ) (Fig. 4B) or the stage of grain development at sampling $\left(\chi^{2}=2.93, P=0.23\right)$ (Fig. 4 C).
Disease assessment and species composition in within-field collections. FHB epidemics developed naturally in the three field settings (SBA, MAR, and VAC). FHB incidence was higher in MAR and VAC fields than in SBA but FHB severity was similar among these fields, averaging $\approx 7 \%$ (Table 2 ). Visibly damaged kernels were generally rare $(<2 \%)$ and were observed at lower frequency in VAC than in the other two fields (Table 2). In total, 189 isolates were obtained from all fields combined. The pathogenic collection accounted for $\approx 50 \%$ of the isolates, whereas the saprophytic and airborne collections accounted for 28.5 and $17.9 \%$ of the isolates, respectively (Table 2).

Across the three fields, FGSC composition in the pathogenic collection was similar to that of the regional survey in RS state. However, species composition differed across the three habitats according to $\chi^{2}$ tests $\left(\chi^{2}=107.48, P=<0.001\right)$ and Fisher's test for use with small sample sizes $(P<0.001)$. Among the 101 isolates in the pathogenic collection, $F$. graminearum with the 15 ADON genotype was dominant $(84.2 \%)$ and $F$. meridionale (NIV) was found in low frequency $(5.0 \%)$. F. cortaderiae (NIV) was found only in diseased kernels of the VAC field and in greater frequency than FmerNIV (Fig. 5C). In the saprophytic population, FmerNIV (68.5\%) and FcorNIV (27.8\%) predominated and only one Fgra15A was observed. Whereas FmerNIV was the dominant type collected from corn stubble of the MAR (western) and SBA fields (central) (Fig. 5A and B), FcorNIV was the most dominant type found in corn stubble of the VAC field (eastern) (Fig. 5C). FGSC composition in the airborne collection more closely

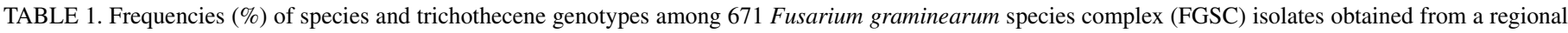
collection of symptomatic wheat spikes from fields in Paraná state (PR) and Rio Grande do Sul state (RS) of Brazil

\begin{tabular}{|c|c|c|c|c|c|c|c|c|}
\hline \multirow[b]{2}{*}{ Species, genotype } & \multicolumn{3}{|c|}{ PR state $(\%)$} & \multicolumn{4}{|c|}{ RS state $(\%)$} & \multirow[b]{2}{*}{ Overall $(\%)$} \\
\hline & 2009 & 2011 & All years & 2009 & 2010 & 2011 & All years & \\
\hline \multicolumn{9}{|l|}{ FGSC } \\
\hline$F$. graminearum & 74.8 & 62.4 & 69.4 & 93.4 & 86.6 & 89.1 & 89.5 & 83.0 \\
\hline$F$. meridionale & 25.2 & 32.3 & 28.2 & 4.1 & 6.0 & 6.5 & 5.5 & 12.8 \\
\hline Other $^{\mathrm{a}}$ & 0.0 & 5.4 & 2.3 & 2.0 & 7.4 & 4.3 & 5.1 & 3.8 \\
\hline \multicolumn{9}{|c|}{ Trichothecene genotype ${ }^{b}$} \\
\hline Deoxynivalenol & 74.8 & 65.6 & 70.8 & 93.9 & 89.8 & 89.1 & 91.0 & 84.5 \\
\hline Nivalenol & 25.2 & 34.4 & 29.2 & 6.1 & 10.2 & 10.9 & 9.0 & 15.4 \\
\hline Subtotal (\%) & 18.3 & 13.8 & 32.1 & 21.9 & 32.1 & 13.7 & 67.8 & 100.0 \\
\hline Subtotal (number) & 123 & 93 & 216 & 147 & 216 & 92 & 455 & 671 \\
\hline
\end{tabular}

a Other species of the FGSC in small frequencies includes F. asiaticum $(n=3), F$. austroamericanum $(n=8)$, and $F$. cortaderiae $(n=17)$.

$\mathrm{b}$ Deoxynivalenol is the combined frequency of 15-acetyldeoxynivalenol (15-ADON) and 3-ADON isolates.

Trichothecene genotype

15-ADON $\circ$ 3-ADON + NIV $\Delta$

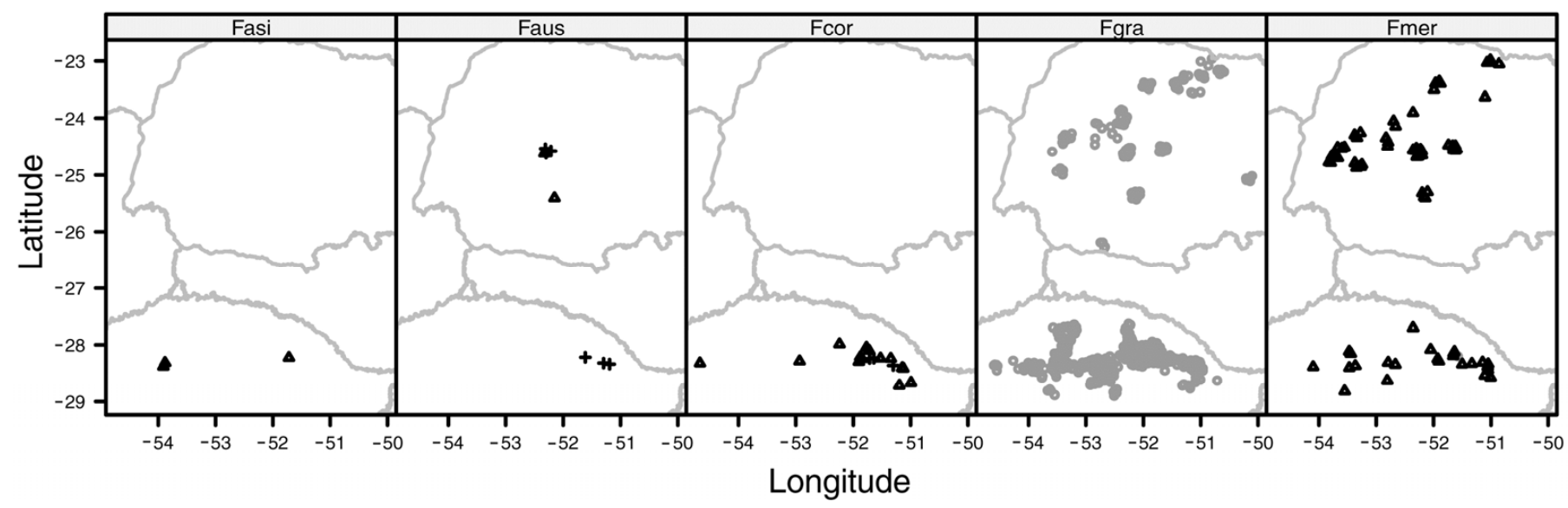

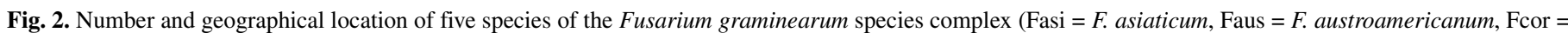

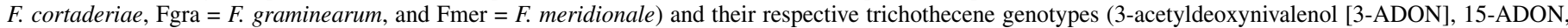

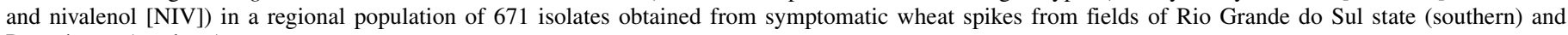
Paraná state (northern). 
matched the pathogenic populations from each of the individual fields. However, the overall composition of the airborne collection was intermediate between that of the pathogenic and saprophytic collections, with Fgra15A accounting for $67.6 \%$ of the isolates and FmerNIV and FcorNIV observed at 17.6 and $14.7 \%$ frequencies, respectively.
Interspecies competitiveness assay. In order to assess the relative pathogenic fitness of the two most common FGSC types encountered in our surveys, potted wheat plants were inoculated during flowering with an equal mixture of Fgra15A and FmerNIV isolates. FHB symptoms were found in most (>94\%) of the inoculated spikes of all cultivars, with the exception of Sumai 3, which

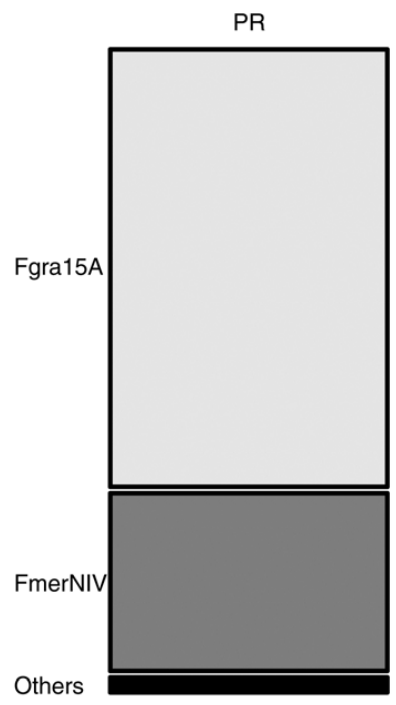

RS

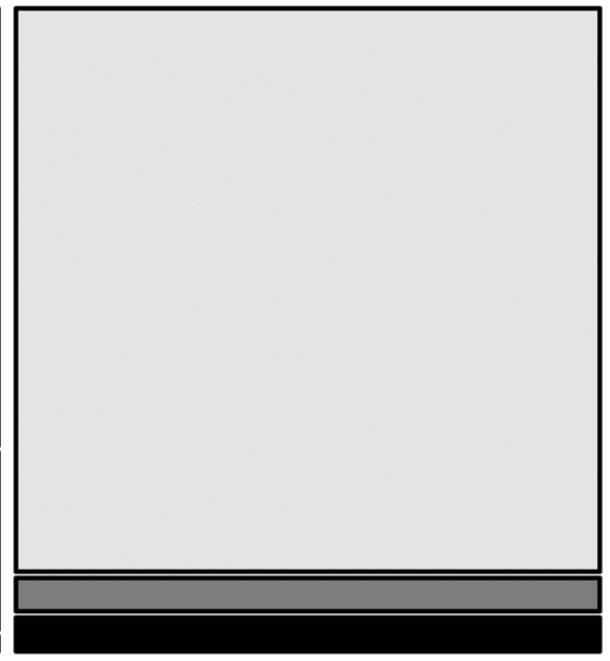

State $(n=671)$

Fig. 3. Mosaic plots for the proportion of isolates of the two most dominant species (Fgra $=F$. graminearum; Fmer $=F$. meridionale) and their respective trichothecene genotype $(15 \mathrm{~A}=15$-acetyldeoxynivalenol $[\mathrm{ADON}], 3 \mathrm{~A}=3-\mathrm{ADON}$, and $\mathrm{NIV}=$ nivalenol $)$ and other less frequently found species and genotypes (F. asiaticum NIV, F. austroamericanum 3A, F. austroamericanum NIV, F. cortaderiae 3A, and F. cortaderiae NIV) obtained from symptomatic spikes in wheat fields sampled in different states.
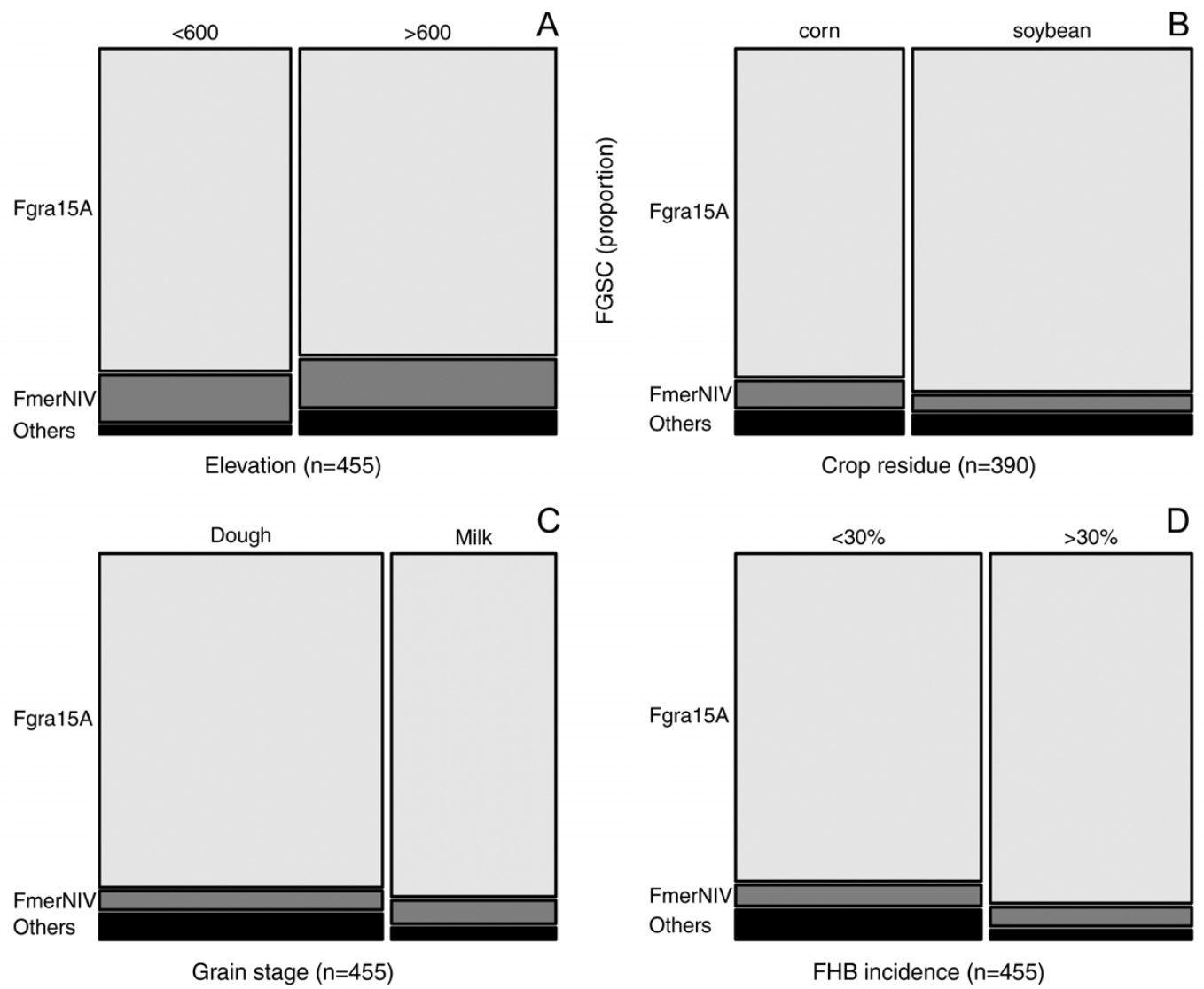

Fig. 4. Mosaic plots for the proportion of isolates of the two most dominant species (Fgra $=$ F. graminearum and Fmer $=$ F. meridionale) and their respective trichothecene genotype $(15 \mathrm{~A}=15$-acetyldeoxynivalenol $[\mathrm{ADON}], 3 \mathrm{~A}=3-\mathrm{ADON}$, and $\mathrm{NIV}=$ nivalenol $)$ and other less frequently found species and genotypes (F. asiaticum NIV, F. austroamericanum 3A, F. austroamericanum NIV, F. cortaderiae 3A, and F. cortaderiae NIV) obtained from symptomatic spikes in wheat fields sampled in fields that varied in $\mathbf{A}$, elevation; $\mathbf{B}$, crop residue from summer crop; $\mathbf{C}$, grain stage during sampling; and $\mathbf{D}$, Fusarium head blight incidence. 
showed only $1 \%$ of inoculated spikes with symptoms. FHB severity was recorded in the three other varieties and the mean values corresponded to their FHB susceptibility levels (BRS $194=$ $75 \%$, Guamirim $=52 \%$, and Frontana $=44 \%$ ). Similarly, $F u$ sarium-damaged kernel incidence values were, on average, 74 , 57, and $48 \%$ for BRS 194, Guamirim, and Frontana, respectively.

In total, 39 isolates were recovered from damaged kernels of each cultivar, with the exception of Sumai 3, which also had no visible FHB symptoms in the kernels. In total, 12 isolates were recovered each from BRS 194 and Frontana and 15 isolates from BRS Guamirim. Most isolates $(89.7 \%)$ were of the Fgra15A type and four isolates of the FmerNIV type were recovered only from BRS Guamirim. The recovery frequency differed significantly between these two species across all cultivars $\left(\chi^{2}=7.68\right.$, $P=0.021)$.

\section{DISCUSSION}

In a previous study, we documented the predominance of Fgra15A causing FHB of wheat in southern Brazil and identified FmerNIV at lower frequency $(3,49)$. In the current study, we analyzed a much larger collection of FGSC isolates, the largest to our knowledge in South America, by using a structured sampling of isolates in fields from multiple years and two states, different regions within the states, and several fields within regions. Additionally, isolates were collected from distinct habitats related to the stages of the fungus life cycle. With this approach, we expanded considerably our knowledge of the diversity and spatial distribution of species and trichothecene genotypes of the FGSC in the main subtropical nontilled wheat agroecosystems of Brazil.

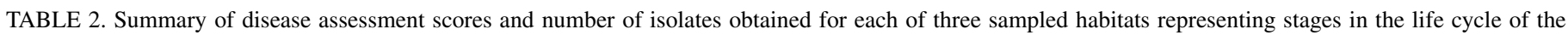
fungus in three fields of the northern Rio Grande do Sul state, Brazil

\begin{tabular}{|c|c|c|c|c|}
\hline \multirow[b]{2}{*}{ Disease, collection } & \multicolumn{3}{|c|}{ Fields } & \multirow[b]{2}{*}{ Sum/mean } \\
\hline & Santa Bárbara (west) & Marau (central) & Vacaria (east) & \\
\hline \multicolumn{5}{|l|}{$\overline{\text { FHB intensity }(\%)^{\mathrm{a}}}$} \\
\hline Incidence & $14.8 \pm 4.2$ & $29.3 \pm 11.8$ & $24.7 \pm 6.3$ & 22.9 \\
\hline Severity & $9.3 \pm 3.4$ & $6.7 \pm 2.8$ & $5.2 \pm 2.4$ & 7.1 \\
\hline FDK & $1.7 \pm 0.5$ & $1.6 \pm 0.4$ & $0.7 \pm 0.4$ & 1.2 \\
\hline \multicolumn{5}{|c|}{ Number of isolates/collection ${ }^{b}$} \\
\hline Saprophytic & 17 & 20 & 17 & 54 \\
\hline Airborne & 6 & 19 & 9 & 34 \\
\hline Pathogenic & 27 & 40 & 34 & 101 \\
\hline Sum & 50 & 79 & 54 & 189 \\
\hline
\end{tabular}

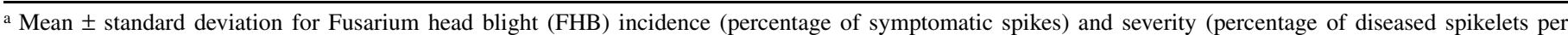
spike) measurements in 200 wheat spikes from eight noninoculated plots, and Fusarium-damaged kernels (FDK) assessed in 100 kernels from eight noninoculated replicates.

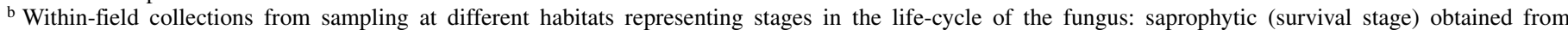
perithecial isolations from corn stubble 1 month prior to flowering, airborne (dispersal stage) from the air above the canopy during flowering, and pathogenic (infection and colonization stage) from Fusarium-damaged mature kernels at harvest.

Santa Bárbara (west, $n=50)$

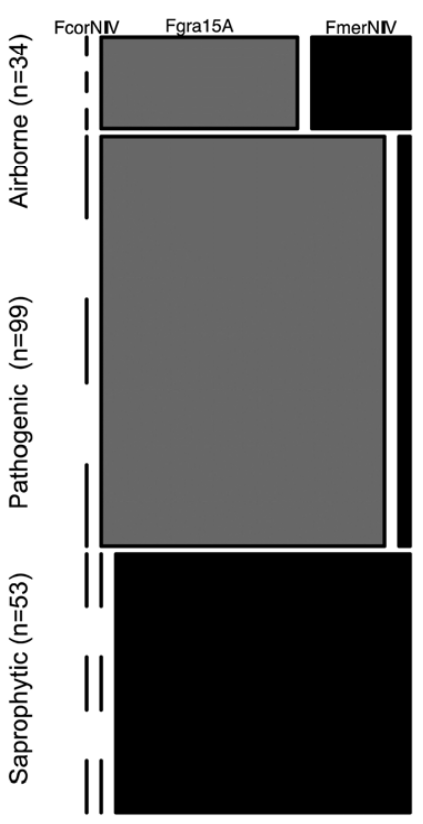

Marau (central, $n=77$ )

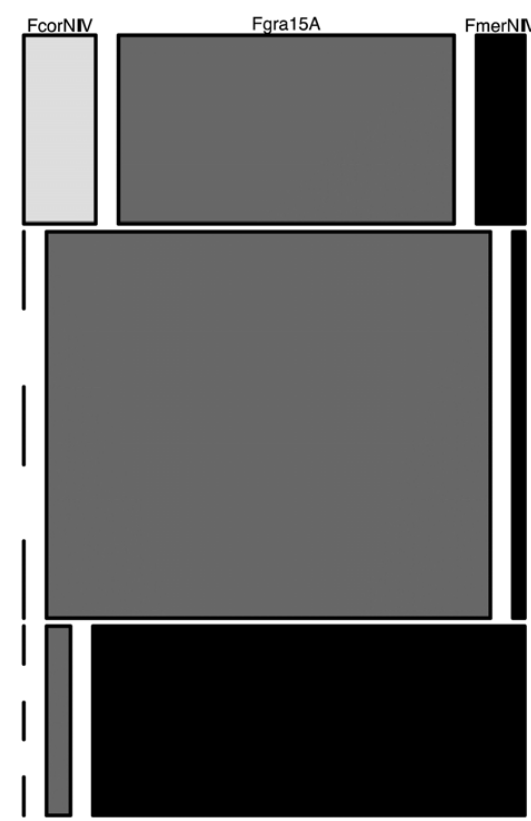

Vacaria (east, $\mathrm{n}=59)$

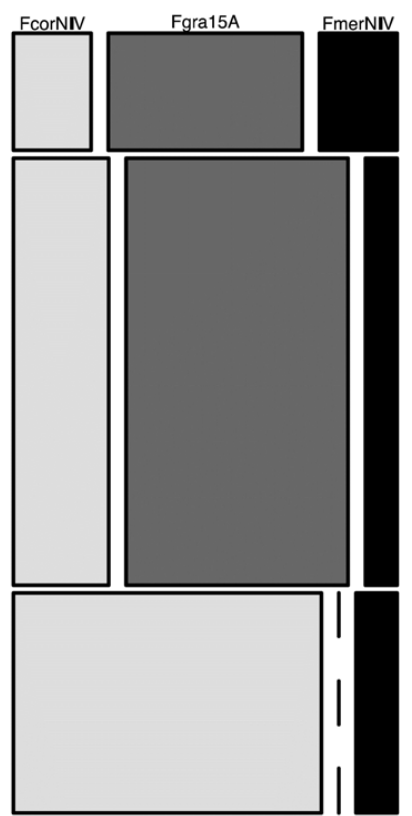

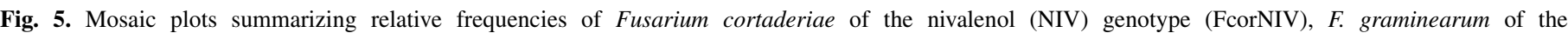

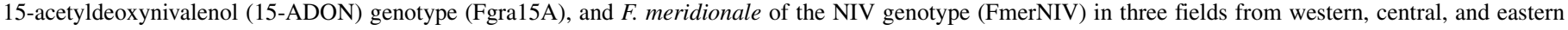

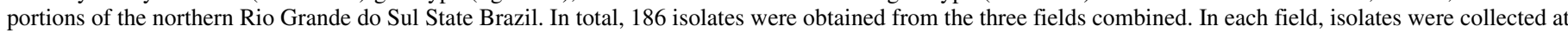

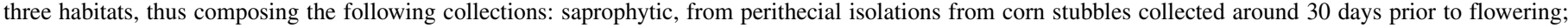

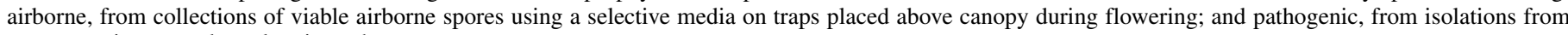
symptomatic mature kernels prior to harvest. 
The expanded survey data confirmed the predominance of $F$. graminearum and demonstrated that $F$. meridionale is also an important regional contributor to FHB of wheat in southern Brazil. Moreover, we provided the first documentation of the relative frequency of three additional FGSC species associated with FHB symptoms in wheat crops of the country. F. austroamericanum, $F$. asiaticum, and $F$. cortaderiae, which were absent from our previous analyses, were found at low frequencies $(<3 \%)$ in the total sample. However, the frequency of $F$. cortaderiae in $\mathrm{RS}$ state was similar to that of $F$. meridionale. Moreover, in our previous survey, we had a very small sample size from the northeastern portion of RS state, where most of the $F$. cortaderiae isolates were encountered in the current study. Hence, it is difficult to hypothesize whether $F$. cortaderiae was present or absent or has increased in frequency since our previous survey in RS state.

F. graminearum likely evolved in North America but this species has a global distribution and is a common cause of FHB in South America $(32,40,56)$. F. meridionale, F. austroamericanum, and $F$. cortaderiae were initially described from South American isolates and are part of a phylogenetic clade that likely originated in South America $(32,46)$. However, F. asiaticum is hypothesized to be Asian endemic and has only recently been identified as a causative agent of FHB of wheat in South America (56). Although all of these three additional FGSC species encountered in this study were reported previously from random collections in Brazil, no information was available for their year of sampling, location, and relative frequency in wheat $(23,32)$.

$F$. graminearum was the only member of the FGSC observed in association with FHB of wheat in Argentina, and was also found to be the most common member of the FGSC on wheat in Uruguay $(40,56)$. As in the current study, $F$. asiaticum, F. cortaderiae, and $F$. austroamericanum were recently found in Uruguayan wheat. However, F. meridionale was not observed among isolates from wheat collected in Argentina or Uruguay, despite our data indicating that $F$. meridionale is a substantial contributor to FHB of wheat in Brazil, especially in the state of Paraná.

In line with our previous findings and those of a number of recent regional surveys $(3,5,21,56,64)$, trichothecene genotype variation was highly structured in relation to species limits. Hence, differences in trichothecene genotype composition were also apparent. NIV accounted for 15.4 and $13.2 \%$ of the isolates obtained from wheat in Brazil and Uruguay, respectively, but was not observed among FGSC isolates from wheat in Argentina. In Brazil, the frequency of the NIV genotype is primarily due to $F$. meridionale, while $F$. asiaticum was the most common species with the NIV genotype found in Uruguay. Taken together, these data indicate that, although Fgra15A is predominant across major wheat-growing areas in South America, FGSC species composition on wheat is different in Brazil, Argentina, and Uruguay.

We found that FmerNIV was present at a much higher frequency in PR state (28.2\% on average) compared with RS state (5.5\% on average), with a corresponding difference in the frequency of the NIV genotype (29.2 and $9.0 \%$, respectively). The basis for this significant regional difference in FGSC composition is not clear but may be related to differences in the relative prevalence of maize production in these two states. Previously, Sampietro and collaborators (44) reported that FmerNIV accounted for $84.8 \%$ of the FGSC isolates from maize in Argentina and $F$. boothii accounted for the rest of the maize isolates, whereas Fgra15A was the only member of the FGSC isolated from wheat in Argentina (40). Sampietro and collaborators (44) interpreted this host-specific difference in pathogen composition as suggestive of a difference in host adaptation, with $F$. meridionale and, possibly, F. boothii being better adapted to colonization of maize in comparison with $F$. graminearum. A large survey of FGSC diversity in South Africa also identified significant differences in FGSC composition between isolates from FHB-infected heads of wheat in which $F$. graminearum predominated and that of maize ears in which $F$. boothii was dominant and $F$. graminearum was absent (5). Based on these data and previously published reports of FGSC diversity on maize, those authors hypothesized that $F$. graminearum may not be the primary FGSC species associated with ear rot of maize worldwide, and that $F$. graminearum may not be as adapted to colonization of maize ears as were other members of the FGSC (5). The acreage of maize crops in PR was estimated to be $\approx 2.5$ million ha in 2011 , which is two times higher than the acreage of maize grown in RS state for the same year (17). The possibility to grow maize twice in a year in PR may favor the build-up of $F$. meridionale populations available to infect wheat, which may partially explain the higher frequency of F. meridionale in PR state.

In addition to significant regional differences in FGSC composition, we observed significant habitat-specific differences in species composition within individual fields sampled in RS state. The most striking result was the uncoupling of saprophytic (maize stubble) and pathogenic (infected kernel) populations that were constituted mainly of FmerNIV/FcorNIV and Fgra15A, respectively. As in the regional survey, Fgra15A was the predominant species isolated from symptomatic kernels in all three fields. However, FmerNIV and FcorNIV accounted for $96.3 \%$ of the isolates obtained from corn stubble in those fields. We speculate that compositional differences among the habitats in the same field also may be reflective of species-specific adaptation to different hosts or environments. The saprophytic population from corn stubble likely reflects the pathogenic population most associated with maize, as suggested (44), but may also reflect a difference in saprophytic fitness favoring FmerNIV and FcorNIV over Fgra15A. Conversely, previous studies have documented that F. graminearum can be more aggressive on wheat than some other members of the FGSC $(16,50,51,56)$. In addition, a previous study showed evidence that species and trichothecene type influenced the relative aggressiveness of different strains toward wheat, with $F$. graminearum and the 15-ADON type being associated with higher aggressiveness relative to $F$. asiaticum or F. graminearum with the NIV type (13). In the present study, we extended this evidence of differences in relative aggressiveness by demonstrating that Fgra15A isolates were much more competitive on wheat than FmerNIV isolates, as shown by the recovery of the former type at significantly higher frequencies following inoculation of wheat cultivars with an equal mixture of isolates representing the two FGSC types.

The observed differences between the saprophytic and pathogenic isolates also suggest that within-field inoculum from stubble may contribute less to FHB in a particular field than the airborne population derived from both within-field and external sources of inocula. The airborne collection from three fields that were separated by an average of $250 \mathrm{~km}$ had a composition of FGSC species and trichothecene genotypes that was intermediate between the pathogenic and saprophytic populations, though more similar to that seen in the pathogenic population. This is consistent with our finding that FGSC composition was not significantly influenced by the previous crop (corn or soybean) observed in an individual field. In some regions of the world, the presence of large amounts of within-field corn stubble is considered an important risk factor for FHB epidemics, especially in temperate climates where the residue decomposition rate is lower than in the subtropics (12,37). In Brazil, virtually all fields are grown under no-till, where abundant small fragments of crop stubble can serve as sources of inoculum. However, numerous alternative hosts are available year round, so that the pathogen population is able to persist in a subtropical climate environment without the limitations imposed by the cold winters of the temperate regions. As such, airborne inoculum of $F$. graminearum 
had been commonly found year round in the wheat agroecosystem in southern Brazil $(9,29,34)$ even before the widespread adoption of no-till in the mid 1980s (41). Studies on the relative importance of different inoculum sources for FHB epidemics in the United States have suggested that background inoculum (i.e., atmospheric settling and washout originating from distant sources) may be a much stronger contributor to FHB infections (19). In fact, the ability for the FHB pathogen to disperse long distances has been proven since viable inoculum of FHB pathogen was found at up to $320 \mathrm{~m}$ above the crop canopy (48) and infecting wheat from $750 \mathrm{~m}$ to many $\mathrm{km}$ from a known source (18). The uniqueness of cropping and climate conditions in Brazil may contribute to the increased diversity of species and genotypes affecting wheat, and may also reduce the relative importance of within-field stubble as a primary source of inoculum.

We found weak evidence that species frequencies were affected by categories of field elevation (600-m threshold), which was a surrogate variable for temperature. Temperature was previously reported to affect the relative frequencies of $F$. graminearum and $F$. asiaticum in China (38), and differences in trichothecene genotype composition were associated with elevation above sea level along the Yangtze River (60). However, physical barriers to the spread of a putative introduced population were hypothesized to explain the effect of elevation studies which reported that temperature differences were not a significant factor behind the regional differences in FGSC composition observed in China $(60,64)$. Climate modeling based on observed distributions indicated that there were few climatic limits on the distribution of $F$. graminearum within the major rain-fed regions of wheat production (4), and the results of a previous study based on controlled-environment data indicated that mycelial growth of $F$. graminearum was equal to or greater than that of $F$. meridionale over a wide range of temperatures (50). Our results indicate that elevation and temperature may influence FGSC composition on wheat in southern Brazil but regional differences in crop rotations and species-specific differences in relative aggressiveness toward wheat likely play a larger role. We also found some evidence that $F$. graminearum prevalence increased with higher FHB incidence scores. However, the effect was modest and consistent with evidence that $F$. graminearum is a more aggressive pathogen of wheat (50), resulting in greater damage to wheat kernels than is observed for $F$. meridionale (51).

In summary, in this study, we have documented the prevalence and distribution of five FGSC species and their trichothecene genotypes associated with FHB of wheat in southern Brazil, identified significant regional differences in FGSC species and trichothecene genotype composition, determined that F. graminearum is more competitive on wheat than $F$. meridionale, and demonstrated that FGSC composition differs significantly among different habitats within individual fields. Taken together, the data presented here suggest that host preference and ecological niche adaptation may regulate FGSC composition and toxin contamination in wheat grown in southern Brazil. Evidence that $F$. meridionale and $F$. cortaderiae with the NIV genotype are regionally significant contributors to FHB may have significant implications for food safety and the economics of cereal production, because nivalenol has been reported to have higher vertebrate toxicity than DON $(27,43)$. As a result of the potential differences in toxicity, the European Scientific Committee on Food has proposed a lower tolerable daily intake limit for NIV $(0.7 \mu \mathrm{g} / \mathrm{kg}$ of body weight) than for DON (1 $\mu \mathrm{g} / \mathrm{kg}$ of body weight) (57). Although maize as the previous crop in an individual field did not influence FGSC composition on wheat, we hypothesize that regional differences in maize production may have a significant influence on pathogen composition and, thus, NIV contamination levels. This indicates the need for analyses of FGSC composition on maize and additional regional surveys of trichothecene contamination levels in grains from Brazil.

\section{ACKNOWLEDGMENTS}

E. M. Del Ponte thanks the CNPq-Conselho Nacional de desenvolvimento Científico e Tecnológico for a research fellowship. P. Spolti thanks the Programa de Pós-graduação em Fitotecnia (UFRGS) and CNPq, for providing a graduate scholarship. This study was partially supported by the United States Department of Agriculture-Agricultural Research Service National Program for Food Safety. We thank N. Orwig and T. Usgaard for excellent technical support. Mention of trade names or commercial products in this article is solely for the purpose of providing specific information and does not imply recommendation or endorsement by the United States Department of Agriculture (USDA). USDA is an equal opportunity provider and employer.

\section{LITERATURE CITED}

1. Alexander, N. J., McCormick, S. P., Waalwijk, C., Van Der Lee, T., and Proctor, R. H. 2011. The genetic basis for 3-ADON and 15-ADON trichothecene chemotypes in Fusarium. Fungal Genet. Biol. 48:485-495.

2. Astolfi, P., dos Santos, J., Schneider, L., Gomes, L. B., Silva, C. N., Tessmann, D. J., and Del Ponte, E. M. 2011. Molecular survey of trichothecene genotypes of Fusarium graminearum species complex from barley in southern Brazil. Int. J. Food Microbiol. 148:197-201.

3. Astolfi, P., Reynoso, M. M., Ramirez, M. L., Chulze, S. N., Alves, T. C. A., Tessmann, D. J., and Del Ponte. E. M. 2012. Genetic population structure and trichothecene genotypes of Fusarium graminearum isolated from wheat in southern Brazil. Plant Pathol. 61:289-295.

4. Backhouse, D. Global distribution of Fusarium graminearum, F. asiaticum and F. boothii from wheat in relation to climate. Eur. J. Plant Pathol., 1-13.

5. Boutigny, A. L., Ward, T. J., Van Coller, G. J., Flett, B., Lamprecht, S. C., O'Donnell, K., and Viljoen, A. 2011. Analysis of the Fusarium graminearum species complex from wheat, barley and maize in South Africa provides evidence of species-specific differences in host preference. Fungal Genet. Biol. 48:914-920.

6. Burgess, L. W., Summerell, B. A., Bullock, S., Gott, K. P., and Backhouse, D. 1994. Laboratory Manual for Fusarium Research, 3rd ed. University of Sydney, Australia.

7. Chandler, E. A., Simpson, D. R., Thomsett, M. A., and Nicholson, P. 2003. Development of PCR assays to Tri7 and Tri13 trichothecene biosynthetic genes, and characterization of chemotypes of Fusarium graminearum, Fusarium culmorum and Fusarium cerealis. Physiol. Mol. Plant Pathol. 62:355-367.

8. Del Ponte, E. M., Fernandes, J. M. C., and Bergstrom, G. C. 2007. Influence of growth stage on Fusarium head blight and deoxynivalenol production in wheat. J. Phytopathol. 155:577-581.

9. Del Ponte, E. M., Fernandes, J. M. C., Pierobom, C. R. 2005. Factors affecting density of airborne Gibberella zeae inoculum. Fitopatol. Bras. 30:55-60.

10. Del Ponte, E. M., Garda-Buffon, J., and Badiale-Furlong, E. 2012. Deoxynivalenol and nivalenol in commercial wheat grain related to Fusarium head blight epidemics in southern Brazil. Food Chem. 132:1087-1091.

11. Desjardins, A., 2006. Trichothecenes. Pages 13-64 in: Fusarium Mycotoxins: Chemistry, Genetics, and Biology. A. Desjardins, ed. The American Phytopathological Society, St. Paul, MN.

12. Dill-Macky, R., and Jones, R. K. 2000. The effect of previous crop residues and tillage on Fusarium head blight of wheat. Plant Dis. 84:71-76.

13. Gale, L. R., Harrison, S. A., Ward, T. J., O'Donnell, K., Milus, E. A., Gale, S. W., and Kistler, H. C. 2011. Nivalenol-type populations of Fusarium graminearum and $F$. asiaticum are prevalent on wheat in southern Louisiana. Phytopathology 101:124-134.

14. Geiser, D. M., Jimenez-Gasco, M. M., Kang, S., Makalowska, I., Veeraraghavan, N., Ward, T. J., Zhang, N., Kuldau, G. A., and O'Donnell, K., 2004. FUSARIUM-ID v. 1.0: A DNA sequence database for identifying Fusarium. Eur. J. Plant Pathol. 110:473-479.

15. Goswami, R. S., and Kistler, H. C. 2004. Heading for disaster: Fusarium graminearum on cereal crops. Mol. Plant Pathol. 5:515-525.

16. Goswami, R. S., and Kistler, H. C. 2005. Pathogenicity and in planta mycotoxin accumulation among members of the Fusarium graminearum species complex on wheat and rice. Phytopathology 95:1397-1404.

17. IBGE: Instituto Brasileiro de Geografia e Estatística. 2013 Levantamento Sistemático da Produção Agrícola. Brasília. http://www.sidra.ibge.gov.br

18. Keller, M. D., Bergstrom, G. C., and Shields, E. J. 2013. The aerobiology of Fusarium graminearum. Aerobiologia. doi:10.1007/s10453-013-9321-3

19. Keller, M. D., Waxman, K. D., Bergstrom, G. C., and Schmale III, D. G. 2010. Local distance of wheat spike infection by released clones of Gibberella zeae disseminated from infested corn residue. Plant Dis. 94:1151-1155.

20. Kimura, M., Tokai, T., O’Donnell, K., Ward, T. J., Fujimura, M., 
Hamamoto, H., Shibata, T., and Yamaguchi, I. 2003. The trichothecene biosynthesis gene cluster of Fusarium graminearum F15 contains a limited number of essential pathway genes and expressed non-essential genes. FEBS Lett. 539:105-110.

21. Lee, J., Chang, I. Y., Kim, H., Yun, S. H., Leslie, J. F., and Lee, Y. W. 2009. Genetic diversity and fitness of Fusarium graminearum populations from rice in Korea. Appl. Environ. Microbiol. 75:3289-3295.

22. Lee, T., Han Y. K., Kim K. H., Yun, S. H., and Lee, Y.W. 2002. Tri13 and Tri7 determine deoxynivalenol- and nivalenol-producing chemotypes of Gibberella zeae. Appl. Environ. Microbiol. 68:2148-2154.

23. Martinelli J. A., Bocchese C. A. C., Xie, W., O'Donnell K, and Kistler H. C. 2004. Soybean pod blight and root rot caused by lineages of the Fusarium graminearum and the production of mycotoxins. Fitopatol. Bras. 29:492-498.

24. McCallum, B. D., Tekauz, A., and Gilbert, J. 2004. Barrage zone formation between vegetatively incompatible Fusarium graminearum (Gibberella zeae) isolates. Phytopathology 94:432-437.

25. McMullen, M., Bergstrom, G. C, De Wolf, E., Dill-Macky, R., Hershman, D., Shaner, G., and Van Sanford, D. V. 2012. A unified effort to fight an enemy of wheat and barley: Fusarium head blight. Plant Dis. 96:17121728.

26. Miller, J. D., Greenhalgh, R., Wang, Y. Z., and Lu, M. 1991. Trichothecene chemotype of three Fusarium species. Mycologia 83:121-130.

27. Minervini, F., Fornelli, F., and Flynn, K. M. 2004. Toxicity and apoptosis induced by the mycotoxins nivalenol, deoxynivalenol and fumonisin B1 in a human erythroleukemia cell line. Toxicol. In Vitro 18:21-28.

28. Mugrabi de Kuppler, A. L., Steiner, U., Sulyok, M., Krska, R., and Oerke, E. C. 2011. Genotyping and phenotyping of Fusarium graminearum isolates from Germany related to their mycotoxin biosynthesis. Int. J. Food Microbiol. 151:78-86.

29. Nicolau, M., and Fernandes, J. M. C. 2012. A predictive model for daily inoculum levels of Gibberella zeae in Passo Fundo, Brazil. Int. J. Agron. http://dx.doi.org/10.1155/2012/795162

30. O'Donnell, K., Kistler, H. C., Cigelnik, E., and Ploetz, R. C. 1998. Multiple evolutionary origins of the fungus causing Panama disease of banana: Concordant evidence from nuclear and mitochondrial gene genealogies. Proc. Natl. Acad. Sci. USA 95:2044-2049.

31. O’Donnell, K., Ward, T. J., Aberra, D., Kistler, H. C., Aoki, T., Orwig, N., Kimura, M., Bjørnstad, A., and Klemsdal, S. S. 2008. Multilocus genotyping and molecular phylogenetics resolve a novel head blight pathogen within the Fusarium graminearum species complex from Ethiopia. Fungal Genet. Biol. 45, 1514-1522.

32. O'Donnell, K., Ward, T. J., Geiser, D. M., Kistler, H. C., and Aoki, T. 2004. Genealogical concordance between the mating type locus and seven other nuclear genes supports formal recognition of nine phylogenetically distinct species within the Fusarium graminearum clade. Fungal Genet. Biol. 41:600-623.

33. Pan, D., Calero, N., Mionetto, A., and Bettucci, L. 2013. Trichothecene genotypes of Fusarium graminearum from wheat in Uruguay. Int. J. Food Microbiol. 162:120-123.

34. Panisson, E., Reis, E. M., and Boller, W. 2002. Quantificação de propágulos de Gibberella zeae no ar e infecção de anteras em trigo. Fitopatol. Bras. 27:484-488.

35. Park, B., Park, J., Cheong, K. C., Choi, J., Jung, K., Kim, D., Lee, Y. H., Ward, T. J., O’Donnell, K., Geiser, D. M., and Kang, S. 2011. Cyber infrastructure for Fusarium: Three integrated platforms supporting strain identification, phylogenetics, comparative genomics and knowledge sharing. Nucleic Acids Res. 39:D640-D646.

36. Pasquali, M., Giraud, F., Brochot, C., Cocco, E., Hoffmann, L., and Bohn, T. 2010. Genetic Fusarium chemotyping as a useful tool for predicting nivalenol contamination in winter wheat. Int. J. Food Microbiol. 137:246253.

37. Pereyra, S. A., and Dill-Macky, R. 2008. Colonization of the residues of diverse plant species by Gibberella zeae and their contribution to Fusarium head blight inoculum. Plant Dis. 92:800-807.

38. Qu, B., Li, H. P., Zhang, J. B., Xu, Y. B., Huang, T., Wu, A. B., Zhao, C. S., Carter J., Nicholson, P., and Liao Y. C. 2008. Geographic distribution and genetic diversity of Fusarium graminearum and $F$. asiaticum on wheat spikes throughout China. Plant Pathol. 57:15-24.

39. Quarta, A., Mita, G., Haidukowski, M., Logrieco, A., Mule, G., and Visconti, A. 2006. Multiplex PCR assay for the identification of nivalenol, 3- and 15-acetyl-deoxynivalenol chemotypes in Fusarium. FEMS 259:7-13.

40. Ramirez, M. L., Reynoso, M. M., Farnochi, M. C., Torres, A. M., Leslie, J. F., and Chulze, S. 2007. Population genetic structure of Gibberella zeae isolated from wheat in Argentina. Food. Addit. Contam. 24:1115-1120.

41. Reis, E. M. Quantificação de propágulos de Gibberella zeae no ar através de armadilhas de esporos. Fitopatol. Bras. 13:324-327. 1988.

42. Reynoso, M. M., Ramirez, M. L., Torres, A. M., and Chulze, S. N. 2011. Trichothecene genotypes and chemotypes in Fusarium graminearum strains isolated from wheat in Argentina. Int. J. Food Microbiol. 145:444-448.
43. Ryu, J. C., Ohtsubo, K., Izumiyama, N., Nakamura, K., Tanaka, T., Yamamura, H., and Ueno, Y. 1988. The acute and chronic toxicities of nivalenol in mice. Fundam. Appl. Toxicol. 11:38-47.

44. Sampietro, D. A., Diaz, C. G., Gonzalez, V., Vattuone, M. A., Ploper, L. D., Catalan, C. A., and Ward, T. J. 2011. Species diversity and toxigenic potential of Fusarium graminearum complex isolates from maize fields in northwest Argentina. Int. J. Food Microbiol. 145:359-364.

45. Sampietro, D. A., Ficoseco, M. E. A., Jimenez, C. M., Vattuone, M. A., and Catalán, C. A. 2012. Trichothecene genotypes and chemotypes in Fusarium graminearu complex strains isolated from maize fields of northwest Argentina. Int. J. Food Microbiol. 153:229-233.

46. Sarver, B. J., Ward, T. J., Gale, L. R., Broz, K., Kistler, H. C., Aoki, T., Nicholson, P., Carter, J., and O'Donnell, K. 2011. Novel Fusarium head blight pathogens from Nepal and Louisiana revealed by multilocus genealogical concordance. Fungal Genet. Biol. 48:1096-107.

47. Schmale, D. G., III, Bergstrom, G. C., and Shields, E. J. 2006. Night-time spore deposition of the Fusarium head blight pathogen, Gibberella zeae, in rotational wheat fields. Can. J. Plant Pathol. 28:100-108.

48. Schmale III, D. G., Ross, S. D., Fetters, T. L., Tallapragada, P., WoodJones, A. K., and Dingus, B. 2012. Isolates of Fusarium graminearum collected 40-320 meters above ground level cause Fusarium head blight in wheat and produce trichothecene mycotoxins. Aerobiologia 28:1-11.

49. Scoz, L. B., Astolfi, P., Reartes, D. S., Schmale, D., Moraes, M. G., and Del Ponte, E. M. 2009. Trichothecene mycotoxin genotypes of Fusarium graminearum sensu stricto and Fusarium meridionale in wheat from southern Brazil. Plant Pathol. 58:344-351.

50. Spolti, P., and Del Ponte, E. M. 2013. Agressividade diferencial de espécies do complexo Fusarium graminearum em interação com o fungicida tebuconazole na redução do rendimento de trigo. Cienc. Rural 43:1569-1575

51. Spolti, P., Barros, N. C., Gomes, L. B., dos Santos, J., and Del Ponte, E. M. 2012. Phenotypic and pathogenic traits of two species of the Fusarium graminearum complex possessing either 15-ADON or NIV genotype. Eur. J. Plant Pathol. 133:621-629.

52. Starkey, D. E., Ward, T. J., Aoki, T., Gale, L. G., Kistler, H. C., Geiser, M. D., Suga, H., Tóth, B., Vara, J., and O'Donnell, K. 2007. Global molecular surveillance reveals novel Fusarium head blight species and trichothecene toxin diversity. Fungal Genet. Biol. 12:1745-1776.

53. Tanaka, T., Yamamoto, S., Hasegawa, A., Aoki, N., Besling, J. R., Sugiura, Y., and Ueno, Y. 1990. A survey of the natural occurrence of Fusarium mycotoxins, deoxynivalenol, nivalenol and zearalenone, in cereals harvested in the Netherlands. Mycopathologia 110:19-22.

54. Thammawong, M., Okabe, M., Kawasaki, T., Nakagawa, H., Okadome, H., Nakajima, T., and Kushiro, M. 2010. Distribution of deoxynivalenol and nivalenol in milling fractions from Fusarium-infected Japanese wheat cultivars. J. Food Prot. 73:1817-1823.

55. Tóth, B., Mesterházy, Á., Horváth, Z., Bartók, T., Varga, M., and Varga, J., 2005. Genetic variability of central European isolates of the Fusarium graminearum species complex. Eur. J. Plant Pathol. 113:35-45.

56. Umpiérrez-Failache, M., Garmendia, G., Pereyra, S., RodríguezHaralambides, A., Ward, T., and Vero, S. 2013. Regional differences in species composition and toxigenic potential among Fusarium head blight isolates from Uruguay indicate a risk of nivalenol contamination in new wheat production areas. Int. J. Food Microbiol. 166:135-140.

57. Van Egmond, H. P., Schothorst, R. C., and Jonker, M. A. 2007. Regulations relating to mycotoxins in food. Anal. Bioanal. Chem. 389:147-157.

58. Ward, T. J., Bielawski, J. P., Kistler, H. C., Sullivan, E., and O'Donnell, K. 2002. Ancestral polymorphisms and adaptive evolution in the tricothecene mycotoxin gene cluster of phytopathogenic Fusarium. Proc. Natl. Acad. Sci. USA99:9278-9283.

59. Ward, T. J., Clear, R. M., Rooney, A. P., O'Donnell, K., Gaba, D., Patrick, S., Starkey, D. E., Gilbert, J., Geiser, D. M., and Nowicki, T. W. 2008. An adaptive evolutionary shift in Fusarium head blight pathogen populations is driving the rapid spread of more toxigenic Fusarium graminearum in North America. Fungal Genet. Biol. 45:473-484.

60. Yang, L., Van der Lee, T., Yang, X., Yu, D., and Waalwijk, C. 2008. Fusarium populations on Chinese barley show a dramatic gradient in mycotoxin profiles. Phytopathology 98:719-727.

61. Yli-Mattila, T. 2010. Ecology and evolution of toxigenic Fusarium species in cereals in northern Europe and Asia. J. Plant Pathol. 92:7-18.

62. Yli-Mattila, T., Gagkaeva, T., Ward, T. J., Aoki, T., Kistler, H. C., and O'Donnell, K. 2009. A novel Asian clade within the Fusarium graminearum species complex includes a newly discovered cereal head blight pathogen from the Far East of Russia. Mycologia 101:841-852.

63. Zadoks, J. C., Chang, T. T., and Konzak, C. F. 1974. A decimal code for the growth stages of cereals. Weed Res. 14:415-421.

64. Zhang, H., Van der Lee, T., Waalwijk, C., Chen, W., Xu, J., Xu, J., Zhang, Y., and Feng, J. 2012. Population analysis of the Fusarium graminearum species complex from wheat in China show a shift to more aggressive isolates. PLoS One 7:1-13. 